\title{
Enhancing Esthetics of Fixed Prosthesis in Anterior Region with an Innovative Pontic Design in conjunction with Periodontal Plastic Surgery- A Case Report
}

Dr Bhagyashree Dange ( $\nabla$ bhagyashree.dange24@gmail.com )

Dr D Y Patil Dental College and Hospital https://orcid.org/0000-0001-8895-0067

Carol Fernandes

Yashwantrao Chavan M Medical R D Foundations Dental College: YCMM and RDF Dental College

\section{Case Report}

Keywords: E pontic, Esthetic, Maxillary anterior region rehabilitation

Posted Date: September 18th, 2020

DOI: https://doi.org/10.21203/rs.3.rs-74742/v1

License: (c) (i) This work is licensed under a Creative Commons Attribution 4.0 International License.

Read Full License 


\section{Abstract}

\section{Background}

The loss of anterior tooth leads to a volumetric deficit of soft and hard tissues, which causes an altered topography. This localized alveolar ridge defect in turn complicates the prosthetic rehabilitation and unesthetic result might lead to patient's social stigma. Such defects can be corrected by either soft or hard tissue augmentation, along with esthetic prosthesis.

Case presentation

This case report describes the augmentation of the sub-epithelial soft tissue graft to rebuild the lost gingival contour for prosthetic rehabilitation missing tooth in esthetic region. The surgical "trap door" approach is explained in detail along with procedure to introduce innovative $\mathrm{E}$ pontic design in prosthesis.

\section{Conclusion}

The ultimate goal of any prosthetic treatment is to enhance esthetics of patient thus aiding in his/her psychological health along with functional stabilization of the compromised arch. The periodontal surgery with gingival friendly prosthetic design increases esthetic outcome of the treatment.

\section{Introduction}

Esthetics and function of the oro-facial region are important aspects of human life, which are affected by anterior tooth loss regardless of personal factors such as age and gender eventually impacting the quality of life. 1 "Ideal emergence profile" the term first used by Stein and Kuwata in 1977 to describe the contours of tooth and crown as they traversed through soft tissue and rose inter-proximally toward the contact area and height of contour facially and lingually. 2

The pontic has been suggested as a more accurate duplication of emergence profile for natural teeth to provide esthetics, the goal of which is to create an illusion that the tooth is emerging from the gingiva with a cuff of tissue surrounding it on the facial aspect3. This case report describes augmentation of deficient alveolar ridge by pouch and graft procedure with connective tissue and use of an innovative pontic design to stabilize the gingival tissue contour in post-surgical healing.

\section{Case Report}

A 22 year old male patient visited the Department of Prosthodontics with the complaint of missing tooth in upper front region of jaw since last 1 year. (Fig: $1 \& 2$ ) The clinical and radiographic examination revealed a Seibert class 1 edentulous defect with concavity on the facial aspect in the anterior region which was aesthetically unpleasing. The patient opted for a fixed partial denture and the consent was recorded. 
Teeth 21 and 23 were prepared to receive all ceramic 3 unit prosthesis. Impressions were made using VPS impression material (3M ESPE) using two step impression technique. The casts were poured in Type III gypsum product. On the maxillary cast, the pontic region was sectioned to mimic the shape of E pontic. 4 The depth of the pontic region was maintained as $2 \mathrm{~mm}$ with slope towards the palatal side $\& 900$ angle towards labio-cervical aspect. After this, wax build up was done on the cast to mimic the natural contours of the teeth involved. Then fabrication of a temporary prosthesis using Self cure bis-GMA acrylic resin (PROTEMP Shade A2) was carried out on the cast. The temporary prosthesis was kept ready for postsurgical cementation.

The surgical procedure of preparing the recipient site to receive the graft from the donor site was carried out after pre-operative mouth rinse using $0.2 \% \mathrm{CHX}$.

The pouch was prepared by placing a horizontal incision on the palatal side of the defect and the dissection was carried out in an apical direction. The mesiodistal entrance incision for the edge of the pouch was made with a long bevel and was started well to the palatal side of the defect with the pouch formation at the buccal side of involved area. (Fig: 3 ).5

The connective tissue graft was harvested with a "trapdoor" technique from the palatal aspect of the maxillary premolars/first molar. A horizontal incision was placed $3 \mathrm{~mm}$ apical to the soft tissue margin perpendicular to the underlying bony surface. Two vertical releasing incisions were made at either end of the primary incision. An incision was then placed from the line of the first incision and directed apically to perform a split incision of the palatal mucosa (Fig:4). A periosteal elevator was used to release the connective tissue graft from the bone. ${ }^{6}$ After harvesting the connective tissue graft, the door was sutured back with $4-0$ vicryl sutures.

The graft was then filled into the pouch (Fig:5) and after proper seating of the palatal graft into the pouch, recipient site was sutured with $5-0$ vicryl sutures. Immediate temporary prosthesis was then fixed with temporary cement (Fig: 6).

Patient was recalled for follow-up and suture removal. At 6 weeks post-surgical appointment, final impressions were made using VPS material with two step technique. All ceramic three unit fixed partial denture was fabricated in the laboratory. At try in appointment, patient confirmed his esthetic and functional satisfaction with prosthesis and it was cemented using dual cure esthetic resin cement (3M ESPE RelyX U200) under isolation. (Fig. 7)

Patient was recalled at regular intervals to check for oral hygiene maintenance and plaque status. The gingival contour was satisfactory with balance to esthetic and functional needs of the patient. (Fig-11)

\section{Discussion}

For the rehabilitation of the compromised function \& esthetics which was a combination of prosthetic procedures along with soft tissue augmentation procedures to attain a proper gingival relationship and 
the decision to select either of the procedures depends on the type of defect and prosthetic rehabilitation. $^{7}$

Langer \& Calagana described connective tissue graft to preserve the tissue color, texture of the underlying mucosa resulting in better esthetics. 8 According to Thoma et al in his review concluded that connective tissue graft provided a greater volume than free gingival graft due to increased vascularity, decreased chances of necrosis and unpredictable shrinkage. 9

The rationale for using this innovative pontic design was it results predictably stable gingival framework with sharp line angles that are formed between tissue side \& 900 walls of pontic are critically important for developing and stabilizing the gingival tissues. The flat surface of this pontic resembles anatomical cross section of tooth at CEJ which also enables entry of dental floss for oral hygiene maintenance which makes this pontic design biocompatible with no evidence of tissue ulceration or food impaction underneath it.4

\section{Conclusion}

The case report demonstrates excellent healing, gingival contour \& buccal convexity showing unwavering results. The success achieved by augmentation of the deficit was one of the critical aspects of prosthetic rehabilitation along with the use of an innovative less known E pontic design.

\section{Declarations}

- Ethics approval and consent to participate-

Not applicable

- Consent for publication-

Not applicable

- Competing interests-

Not applicable

- Funding-

Not applicable

- Authors' contributions-

Both authors have participated in clinical protocol and manuscript writing.

- Acknowledgements- 
None

\section{References}

1. AL-Omiri MK, Karasneh JA, Lynch E, Lamey PJ, Clifford TJ. Impacts of missing upper anterior teeth on daily living. International dental journal. 2009 Jun;59(3):127-32.

2. Stein RS. Periodontal dictates for esthetic ceramometal crowns. The Journal of the American Dental Association. 1987 Dec;115(1):63E-73E.

3. Abrams L. Augmentation of the deformed residual edentulous ridge for fixed prosthesis. Compend C. Educ Gen Dent. 1980;1:205-13.

4. Korman RP. Enhancing esthetics with a fixed prosthesis utilizing an innovative pontic design and periodontal plastic surgery. Journal of Esthetic Restorative Dentistry. 2015 Jan;27(1):13-28.

5. Agarwal A, Gupta ND. Alveolar ridge augmentation by connective tissue grafting using a pouch method and modified connective tissue technique: A prospective study. Dental research journal. 2015 Nov;12(6):548.

6. Pandit N, Khasa M, Gugnani S, Malik R, Bali D. Comparison of two techniques of harvesting connective tissue and its effects on healing pattern at palate and recession coverage at recipient site. Contemporary Clinical Dentistry. 2016 Jan;7(1):3.

7. Studer ST, Kadl PA, Glauser RO, Scharer P. Semi-quantitative short-term results of three different soft tissue augmentation procedures in multiple tooth defects. Schweizerische Monatsschrift Fur Zahnmedizin. 1998;108:68-74.

8. Langer B, Calagna L. The subepithelial connective tissue graft. The Journal of prosthetic dentistry. 1980 Oct 1;44(4):363-7.

9. Thoma DS, Benić GI, Zwahlen $\mathrm{M}$, Hämmerle $\mathrm{CH}$, Jung RE. A systematic review assessing soft tissue augmentation techniques. Clin Oral Implants Res. 2009 Sep;20:146-65.

\section{Notes}

Figure $3,4,9$ and 10 are not available in this version of the manuscript.

Figure captions for 1 to 11 are not available in this version of the manuscript.

\section{Figures}




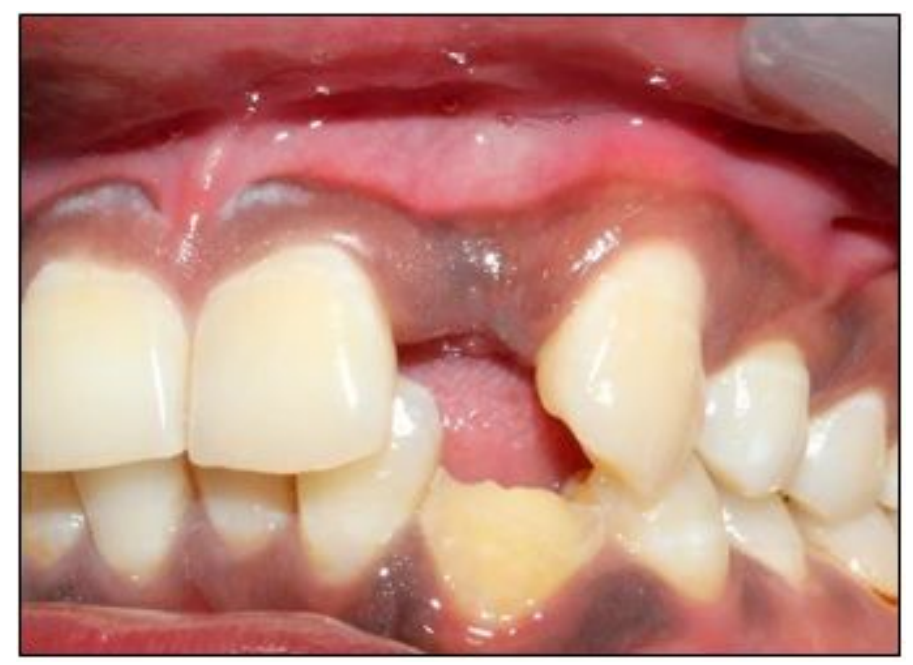

Figure 1

Captions are not available in this version of the manuscript.

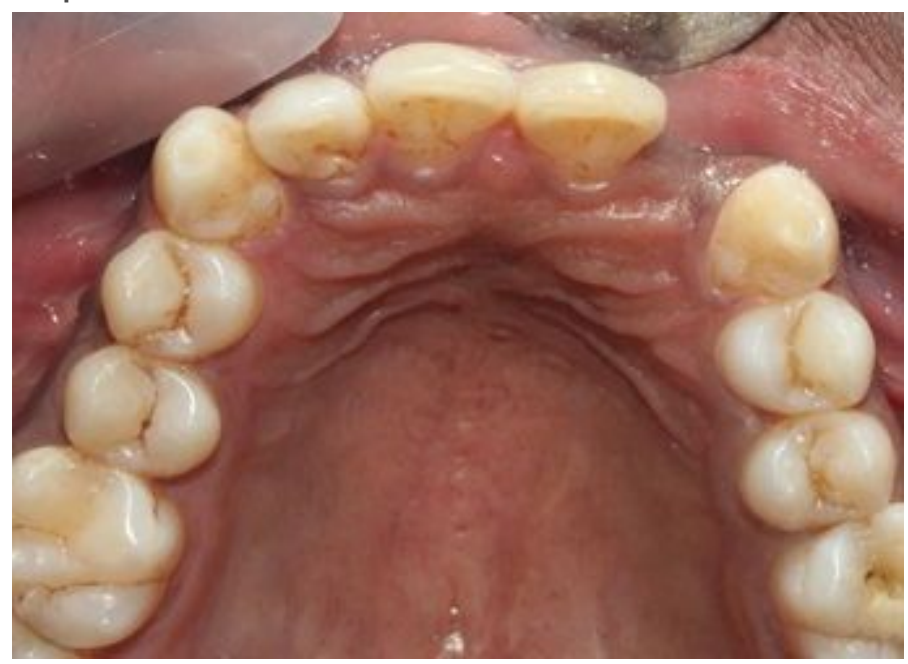

Figure 2

Captions are not available in this version of the manuscript.

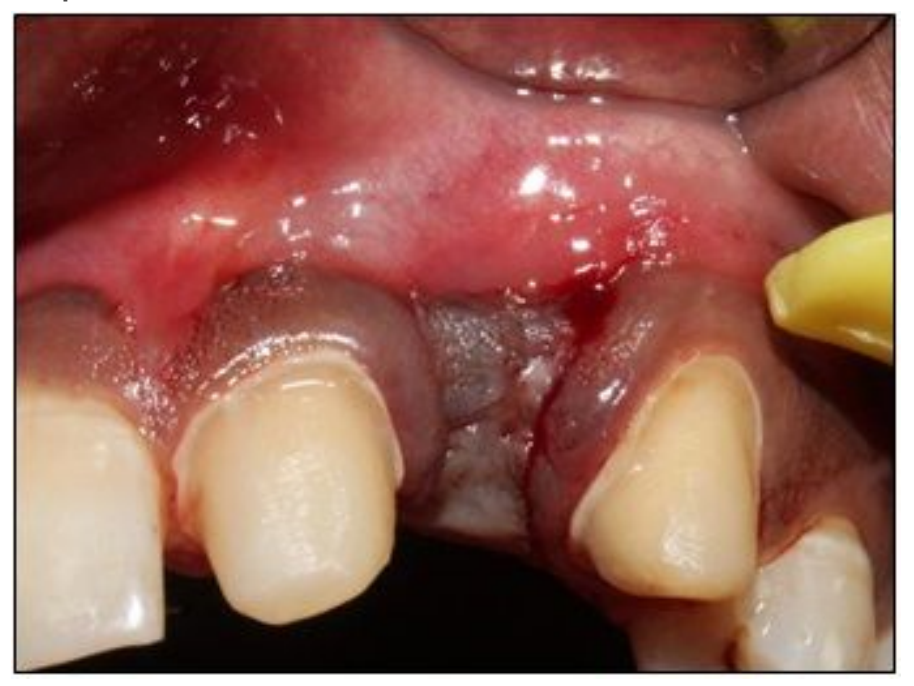


Figure 3

Figure 5 Captions are not available in this version of the manuscript.

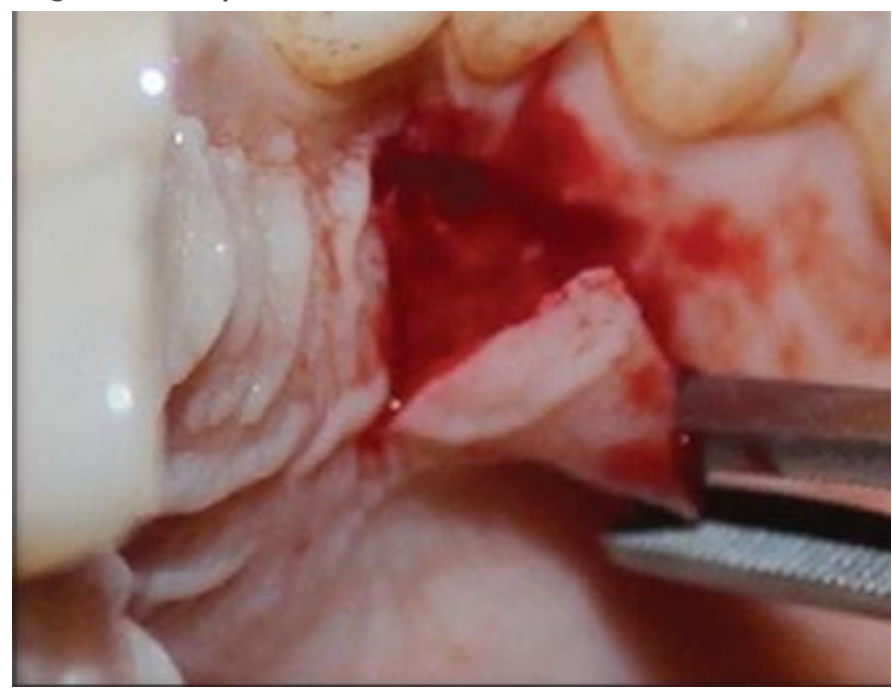

Figure 4

Figure 6 Captions are not available in this version of the manuscript.

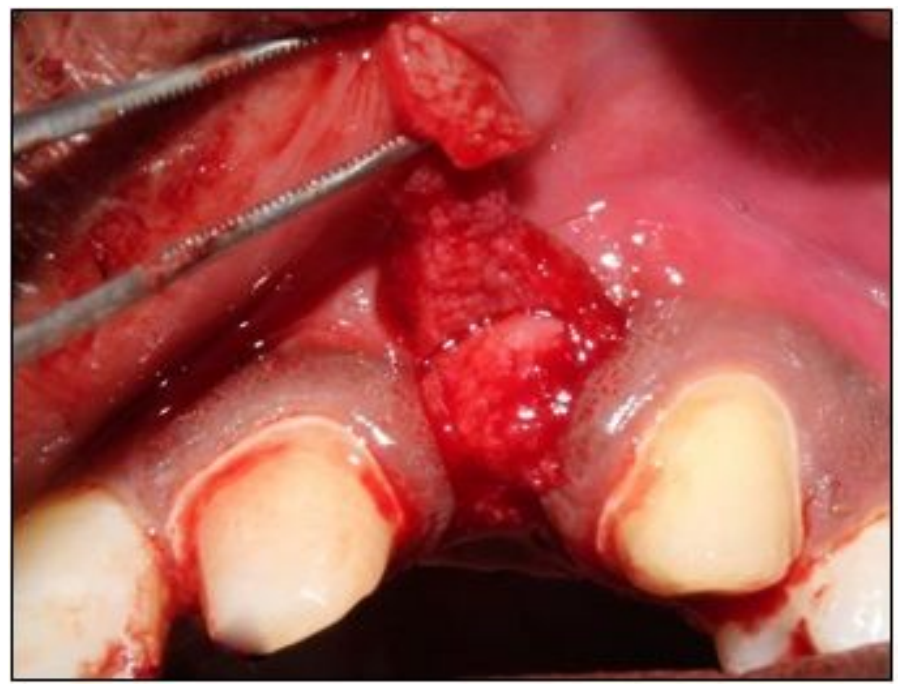

\section{Figure 5}

Figure 7 Captions are not available in this version of the manuscript. 


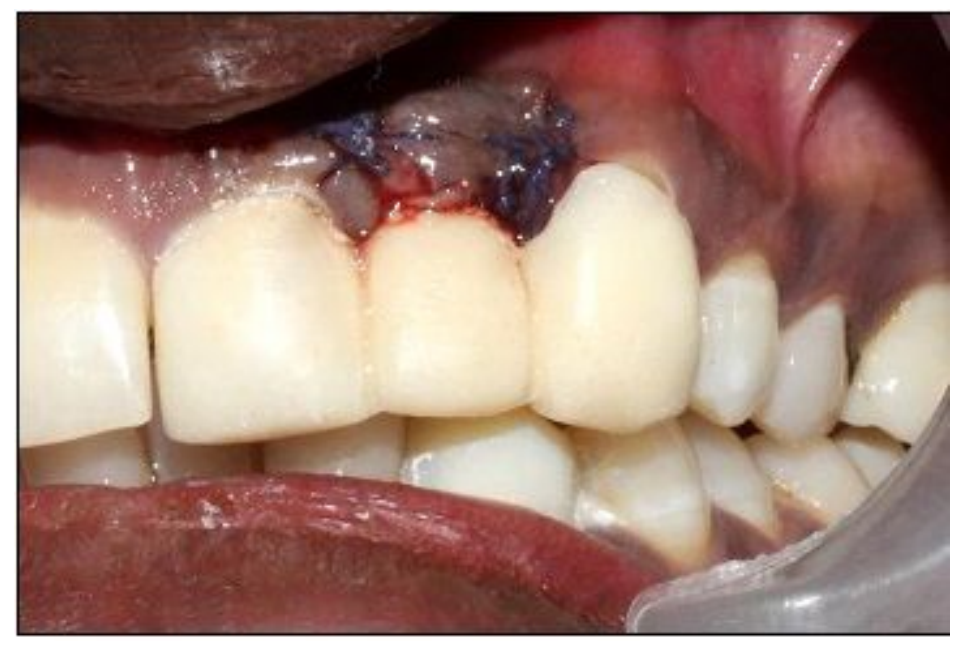

Figure 6

Figure 8 Captions are not available in this version of the manuscript.

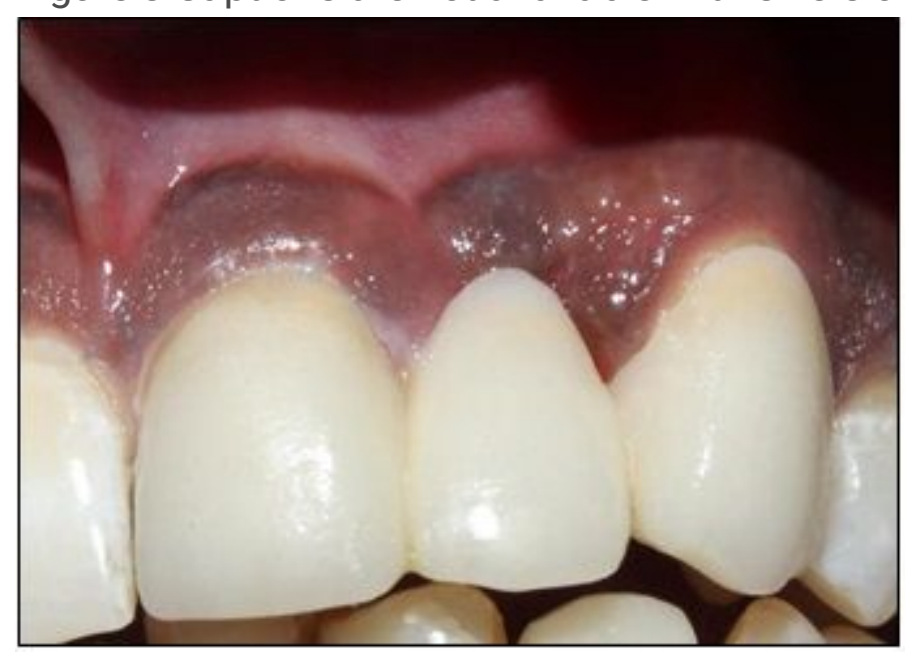

\section{Figure 7}

Figure 11 Captions are not available in this version of the manuscript. 